\title{
Comparison of a Bridge Immunoassay with Two Bioassays for Thyrotropin Receptor Antibody Detection and Differentiation
}

Authors

Stephanie Allelein ${ }^{1}{ }^{*}$, Tanja Diana ${ }^{2}{ }^{*}$, Margret Ehlers ${ }^{1}$, Michael Kanitz², Derik Hermsen ${ }^{3}$, Matthias Schott ${ }^{1 \S}$, George J. Kahaly2§

Affiliations

1 Medical Faculty, Division for Specific Endocrinology, University of Düsseldorf, Düsseldorf, Germany

2 Department of Medicine I, Molecular Thyroid Research Laboratory, Johannes Gutenberg University (JGU) Medical Center, Mainz, Germany

3 Institute of Clinical Chemistry and Laboratory Diagnostics, Medical Faculty, University of Düsseldorf, Düsseldorf, Germany

Key words

TSH receptor functional antibodies, bridge immunoassay, cell-based bioassay

$\begin{array}{ll}\text { received } & 15.03 .2019 \\ \text { accepted } & 02.05 .2019\end{array}$

Bibliography

DOI https://doi.org/10.1055/a-0914-0535

Horm Metab Res 2019; 51: 341-346

(c) Georg Thieme Verlag KG Stuttgart · New York

ISSN 0018-5043

Correspondence

Matthias Schott, MD, PhD

Medical Faculty,

Division for Specific Endocrinology,

University of Düsseldorf,

Moorenstraße 5,

40225 Düsseldorf,

Germany

Tel.: +49/211/81 04860, Fax: +49/211/8117860

matthias.schott@med.uni-duesseldorf.de

\section{ABSTRACT}

A rapid and fully automated chemiluminescent immunoassay for the detection of thyrotropin receptor autoantibodies (TSHR$\mathrm{Ab}$ ) based on a bridge technology was compared with two bioassays that measure either stimulating (TSAb) or blocking (TBAb) antibodies for the detection and differentiation of TSHRAb. A total of 229 patients with various thyroid disorders [151 with Graves' disease (GD), 35 with Hashimoto's thyroiditis (HT), 32 with nodular goiter, and 11 with thyroid cancer] were included. The bridge immunoassay was performed according to the manufacturer's instructions (cut-off $>0.55 \mathrm{IU} / \mathrm{I}$ ). TSAb and TBAb were measured with reporter bioassays. Blocking activity was defined as percent inhibition of luciferase expression relative to induction with bovine TSH alone (cut-off $>34 \%$ inhibition). TSAb was reported as percentage of specimen-to-reference ratio (>140 SRR\%). The 3 TSHR-Ab assays were negative in all patients with benign euthyroid nodular goiter and differentiated thyroid cancer. In contrast, in all patients with GD, irrespective of the disease duration, TSHR-Ab positivity was present in 127 of 151 (84\%) and 140 (93\%) for the bridge assay and TSAb bioassay, respectively $(p<0.001)$. Fifteen of 151 (10\%) GD samples were positive in the TSAb bioassay but negative in the bridge assay. The bridge assay and the TSAb bioassay correlated positively $(r=0.39, p<0.0001)$ in patients with $G D$. Both assays detected TSHR-Ab in all ten untreated hyperthyroid patients with GD. In GD patients with a duration of less than six months, $27 / 29$ (93\%) and 28 (97\%) were TSHR-Ab positive with the bridge and TSAb bioassay, respectively. In comparison, TSHR-Ab were present in two of $35(6 \%)$ and five (14\%) HT patients with the bridge and TSAb bio-assay, respectively. TSHR blocking antibodies were present in one (3\%) patient with $\mathrm{HT}$ and in two (1\%) patients with GD; these two GD patients were also bridge assay positive but TSAb bioassay negative. In conclusion, the bridge immunoassay and both bioassays are highly sensitive for the detection of TSHR-Ab. The bridge assay is, however, also positive in the presence of TSHR blocking antibodies detected in a TBAb bioassay.

\footnotetext{
* SA and TD share first authorship.

$\S \quad$ MS and GJK share senior authorship.
} 


\section{Introduction}

Graves' disease (GD) is an autoimmune disease caused by autoantibodies (Ab), which bind to the thyrotropin receptor (TSHR) on the surface of thyrocytes, resulting in uncontrolled overproduction of thyroid hormones [1-3]. For quantification of TSHR-Ab and confirmation of the clinical diagnosis, various types of assay technology are commonly used in laboratory medicine. The most widely used assays measure the competition between binding of TSHR-Ab and TSH $[4,5]$ or an anti-TSHR directed human monoclonal autoantibody [6]. In contrast to these competition assays, cell-based bioassays measure increased production of either cyclic AMP or cyclic AMP-dependent luciferase activity [7-11]. These bioassays exhibit high sensitivity and specificity but require experienced lab personal.

Recently, an assay system has been reported, which directly detects the concentration of TSHR-Ab in sera of patients by applying bridge technology [12]. It has been postulated that the bridge assay exclusively detects stimulating TSHR-Ab (TSAb). In this assay, TSHR$A b$ are detected by binding one antibody arm to a capture receptor on the solid phase and bridging with the other arm to a detection receptor giving a signal, thus the term bridge assay. The assay uses a mutant chimeric TSHR (MC4) and detects TSHR-Ab based on an understanding of the structure of the extra-cellular domain of the TSHR and its interactions with anti-TSHR-Ab [12-14]. In previous reports, the MC4 chimeric construct was postulated to specifically detect TSAb [15]. These claims, however, have neither been reproduced nor verified and numerous studies have used a MC4-expressing cell line to successfully measure and quantify blocking TSHR-Ab (TBAb) in sera of patients with autoimmune thyroid disease [16-23]. This bridge immunoassay has been clearly shown to have a high clinical sensitivity for the detection of GD and discrimination from other thyroid diseases [12, 20,21]. Up to now, however, there is neither evidence for the exclusive detection of stimulating TSHR-Ab nor a potential differentiation of TSHR-Ab functionality when using this automated bridge immunoassay. Therefore, the objective of this present work was to compare this bridge immunoassay with two functional bioassays for TSHR-Ab detection and differentiation.

\section{Patients and Methods}

\section{Patients}

A total of 229 patients were included in the study. Among them 151 had GD, of those 10 patients had newly diagnosed untreated disease while $141 \mathrm{GD}$ patients were on antithyroid drugs $(n=29,<6$ months, $n=18<12$ months, and $n=82>12$ months, respectively, after initial diagnosis; in $12 \mathrm{GD}$ patients the time point of initial diagnosis is not known). Additional 35 patients with autoimmune Hashimoto's thyroiditis (HT), 32 with non-autoimmune, euthyroid nodular thyroid disease, and 11 with differentiated thyroid cancer (8 papillary and 3 follicular) were enrolled in this study. Criteria for diagnosis of GD were based on characteristic symptoms and signs characteristics, that is, biochemical hyperthyroidism or endocrine orbitopathy, initially documented positivity with conventional TSHR-Ab binding immunoassay (Cobas, Roche Diagnostics $\mathrm{GmbH}$, Mannheim, Germany) [6], hypoechogenicity and increased blood flow in thyroid ultrasound and/or increased uptake in the technetium thyroid scintigraphy. Biochemical hyperthyroidism was defined as increased serum concentrations of free thyroxine $\left(\mathrm{fT}_{4}\right)$, increased free triiodothyronine $\left(\mathrm{fT}_{3}\right)$, and decreased or suppressed basal thyrotropin (TSH). Autoimmune HT was defined as the presence of increased serum levels of anti-thyroperoxidase (TPO) Ab, eu- or hypothyroidism and hypoechogenicity with thyroid ultrasound.

The study has been approved by the Ethical Committee of the Heinrich-Heine-University Duesseldorf (No. 5380). All experiments have been conducted according to the principles expressed in the Declaration of Helsinki.

\section{Bridge immunoassay}

The bridge immunoassay (Immulite 2000, Siemens) used is an automated, two-cycle, chemiluminescent immunoassay. As described by the manufacturer, the assay employs a pair of recombinant hTSHR constructs in a bridging immunoassay format. The capture receptor is immobilized on the solid phase (polystyrene bead). The signal receptor is an alkaline phosphatase labeled recombinant hTSHR in a buffer solution. In the first cycle, the sample (required volume $50 \mu \mathrm{l}$ ) is incubated with the solid phase for $30 \mathrm{~min}$, allowing the TSHR-Ab in the sample to bind through one arm to the capture receptor. Next, centrifugal washes remove residual sample. In the second cycle, the signal receptor is added to the reaction tube and incubated for $30 \mathrm{~min}$. The complexed TSHR-Ab bind the signal receptor through the second arm, forming a bridge. Unbound signal receptor is then removed by centrifugal washes. Finally, chemiluminescent substrate is added to the reaction tube and a signal is generated in direct relation to the amount of TSHR-Ab in the sample. Incubation cycles are 2 times $30 \mathrm{~min}$. The measuring range is: $0.1-40.0 \mathrm{IU} / \mathrm{l}$ and the cut-off is $0.55 \mathrm{IU} / \mathrm{l}$.

\section{Bioassay for stimulating TSH-receptor antibodies}

Serum TSHR stimulating antibody (TSAb) levels were measured in a blinded manner with a FDA-cleared cell-based assay (Thyretain, Quidel, San Diego, CA, USA) according to the manufacturer's instructions [8, 24]. Briefly, Chinese Hamster Ovary (CHO)-MC4 cells were seeded and grown to confluent cell monolayers in 96-well plates for 15-18 h. Patient and control samples (required volume $30 \mu \mathrm{l}$ ), as well as positive, reference and normal controls were diluted 1:11 in reaction buffer ( $R B$, Quidel, San Diego, CA, USA), added to the cell monolayers, and each plate was incubated for $3 \mathrm{~h}$ at $37{ }^{\circ} \mathrm{C}, 5 \% \mathrm{CO}_{2}$. Subsequently, the $\mathrm{CHO}-\mathrm{MC} 4$ cells were lysed and the relative light unit values were quantified in a luminometer (Infinite M200; Tecan, Crailsheim, Germany). The assay cut-off is at a percentage specimen-to-reference-ratio (SRR) of $140 \%$. All sera were measured in duplicates, data are expressed as mean values.

\section{Bioassay for blocking TSH-receptor antibodies}

Serum TSHR blocking antibodies (TBAb) levels were measured according to the manufacturer's instructions of the CE-marked cellbased assay [ 16,18$]$. The cut-off, initially $40 \%$ inhibition (I), was lowered in early 2017 to $34 \%$ I. All sera (required volume $30 \mu \mathrm{l}$ ) were measured in duplicates, data are expressed as mean values. 
- Table 1 Demograhic data of all study patients.

\begin{tabular}{|l|r|l|l|}
\hline Collective & $\mathbf{n}$ & $\begin{array}{l}\text { Age (years, } \\
\text { range) }\end{array}$ & Gender \\
\hline Graves' disease & 151 & $45(18-87)$ & $91 \%$ female \\
\hline Hashimoto's thyroiditis & 35 & $43(17-69)$ & $77 \%$ female \\
\hline Benign nodular goiter & 32 & $63(19-85)$ & $84 \%$ female \\
\hline Thyroid cancer & 11 & $58(18-72)$ & $73 \%$ female \\
\hline
\end{tabular}

Age, gender and prevalence of TSHR-Ab positivity are shown in the four; different groups with thyroid diseases.

\begin{tabular}{l|l|l|l|l|}
$\begin{array}{l}\text { Table } 2 \text { Serological data. } \\
\text { Collective }\end{array}$ & $\mathbf{n}$ & $\begin{array}{l}\text { Bridge } \\
\text { Assay }\end{array}$ & $\begin{array}{l}\text { TSAb } \\
\text { Bioassay }\end{array}$ & $\begin{array}{l}\text { TBAb } \\
\text { Bioassay }\end{array}$ \\
\hline Graves' disease * & 151 & $127(84 \%)$ & $140(93 \%)$ & $2(1.3 \%)$ \\
\hline Hashimoto's thyroiditis & 35 & $2(6 \%)$ & $5(14 \%)$ & $1(3 \%)$ \\
\hline Benign nodular goiter & 32 & 0 & 0 & 0 \\
\hline Thyroid cancer & 11 & 0 & 0 & 0
\end{tabular}

TSAb: TSH receptor stimulating antibodies; TBAb: TSH receptor blocking antibodies; " GD patients including those with long term disease duration.

\section{Statistical analysis}

Prism software (PRISM 6, GraphPad Software, Inc., La Jolla, CA, USA) was used for calculation of statistical significances and for graphical presentation. For data showing a Gaussian distribution, the unpaired t-test was performed. For not normally distributed data, the Mann-Whitney U-test was used. For correlation analyses, the Pearson correlation coefficient was calculated. $\mathrm{p}$-Values $<0.05$ were considered as significant.

\section{Results}

\section{Demographic data}

The demographic data of all study patients with the various thyroid diseases are shown in $>$ Table 1.

\section{Detailed comparison of all three TSHR-Ab assays}

The 3 assays were clinically specific and negative in all patients with non-toxic euthyroid benign nodular goiter and/or differentiated thyroid cancer. In contrast, the bridge immunoassay and the cellbased bioassay were clinically highly sensitive in detecting TSHRAb in GD patients $(p<0.0001)$ ( $($ Table 2$)$. In patients with GD, TSHRAb positivity was present in 127 of 151 (84.1\%) and 140 (92.7\%) for the bridge assay and TSAb bioassay ( $\mathbf{F i g} . \mathbf{1}$ ), respectively $(p<0.001)$. Fifteen of 151 (10\%) GD samples were TSAb bioassay positive however bridge assay negative. Among the 151 GD pa- tients, $125(83 \%)$ tested concomitantly positive in the TSAb bioassay and in the bridge assay. Both assays detected TSHR-Ab in all ten untreated hyperthyroid GD patients ( $\bullet$ Fig. 2 ). In GD patients with a duration of less than 6 months, 27/29 (93\%) and 28 (97\%), respectively, were TSHR-Ab positive with the bridge- and TSAb bioassay. In all GD patients, the bridge assay and the TSAb bioassay correlated positively (Pearson, $r=0.39, p<0.0001$ ) ( $>$ Fig. 3 ).

In comparison, TSHR-Ab were present in 2 of 35 (5.7\%) and 5 (14.3\%) HT patients with the bridge- and TSAb bio-assay, respectively ( $>$ Fig. 1). One (2.9\%) patient with HT and two (1.3\%) patients with GD were positive in the TBAb bioassay; these two GD patients were also positive in the bridge assay but negative in the TSAb bioassay. The two TBAb positive samples were also positive with the COBAS (Roche) binding assay.

\section{Discussion}

The recent guidelines of both the American [25] and European [26] Thyroid Associations for the management of Graves' hyperthyroidism strongly recommend the measurement of TSHR-Ab for the accurate and timely diagnosis/differential diagnosis of GD. Indeed, compared to other diagnostic approaches, that is, thyroid scan and/ or ultrasound, TSHR-Ab measurement is more specific and less expensive demonstrating the clinical utility and clinical relevance of these antibodies as a reliable biomarker of the disease.

The present work reports the results of a one-to-one comparison of a recently introduced automated "bridge" immunoassay and two FDA-cleared and/or CE-marked cell-based bioassays for the detection of functional TSHR-Ab in patients with autoimmune and non-autoimmune thyroid diseases. Both assays were highly sensitive for detecting TSHR-Ab in hyperthyroid patients with untreated GD. For the bridge immunoassay, this has been shown already in cross-sectional trials $[12,27,28]$. In these three cited studies, the TSHR-Ab measured with the bridge assay correlated positively with the serum free T4 levels. The same story holds true for the clinical sensitivity of the TSAb bioassay both in children [29] as well as in adults [20,21] with GD. Furthermore, on careful review of the 4 articles that evaluated the bridge assay $[12,27,28,30]$ only one study [12] looked at the interference with a monoclonal blocking TSHR$A b$ and showed a positive TSHR-Ab measurement in one of three hypothyroid, TSHR-Ab positive GD patients. These data suggest that the bridge assay may not differentiate between stimulatory and blocking antibodies although in the two other hypothyroid, TBAb-positive GD patients, the bridge assay showed negative results. This was also underlined in a study of 120 consecutive well-characterized and well-defined patients with autoimmune thyroid diseases which included both commercially available purely-stimulating human monoclonal antibody (M22) and blocking human monoclonal antibody (K1-70) as well as polyclonal Ab (patient sera). This study demonstrated the variable sensitivity and analytical specificity of seven TSHR-Ab immunoassays [20, 21, $23,31]$. In contrast, other studies comparing various TSHR-Ab assays did not specifically look at the specificity, functionality and differentiation of measured TSHR-Ab [27, 28, 30].

In the present study, we demonstrated a significant but low correlation between TSHR-Ab detected in the bridge assay and TSAb measured in the bioassay and found concordant results in $83 \%$ 


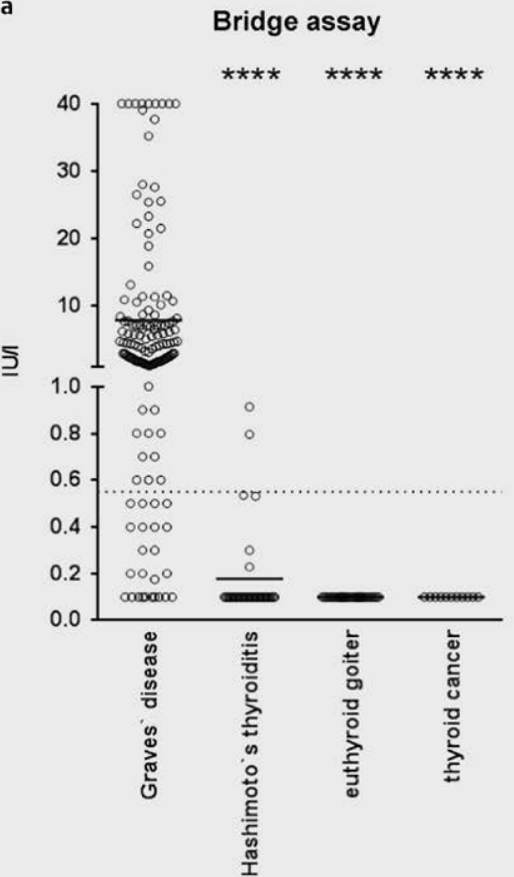

Bioassay for stimulating TSHR-Ab

c

Bioassay for blocking TSHR-Ab
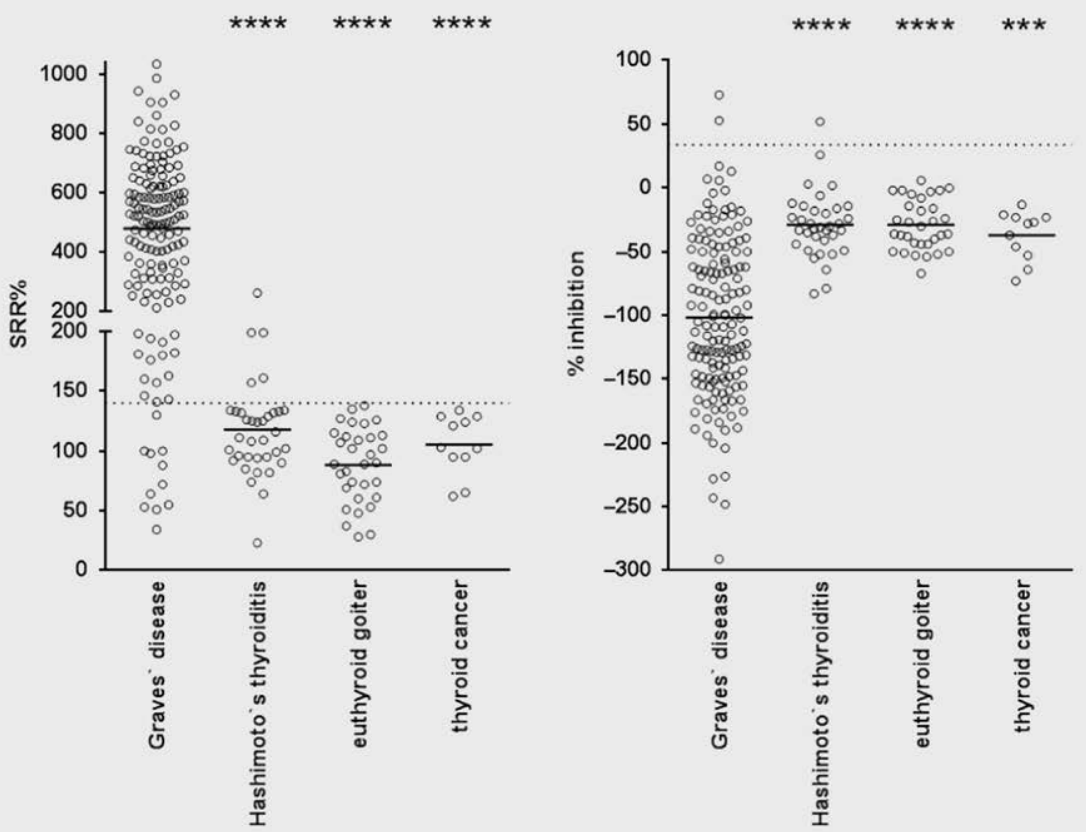

Fig. 1 Comparison of the bridge assay and both bioassays for stimulating and blocking TSHR-Ab in patients with various thyroid diseases: Prevalence of the TSH receptor antibody positivity with the three assays in patients with Graves' disease (GD), autoimmune Hashimoto's thyroiditis (HT), non-autoimmune, euthyroid nodular goiter (goiter), and differentiated thyroid cancer. The cut-offs for the three bridge, stimulatory (TSAb), and blocking (TBAb) bio-assays are $0.55 \mathrm{IU} / \mathrm{I}, 140$ SRR $\%$, and $34 \%$ inhibition, respectively.

a

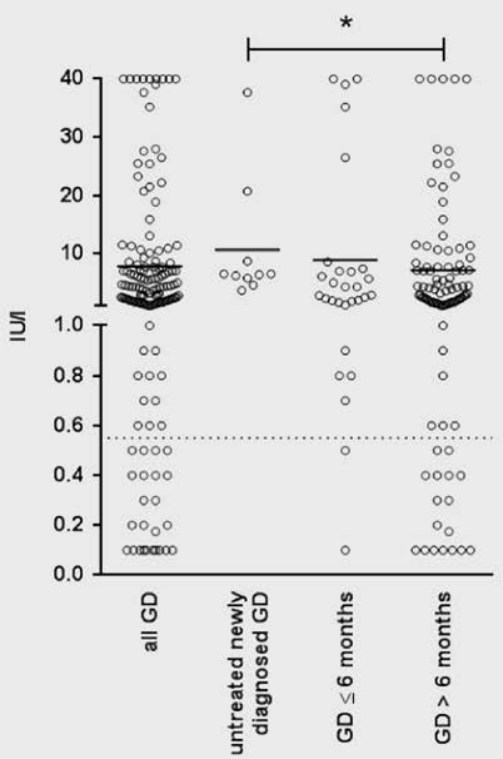

b

Bioassay for stimulating TSHR-Ab

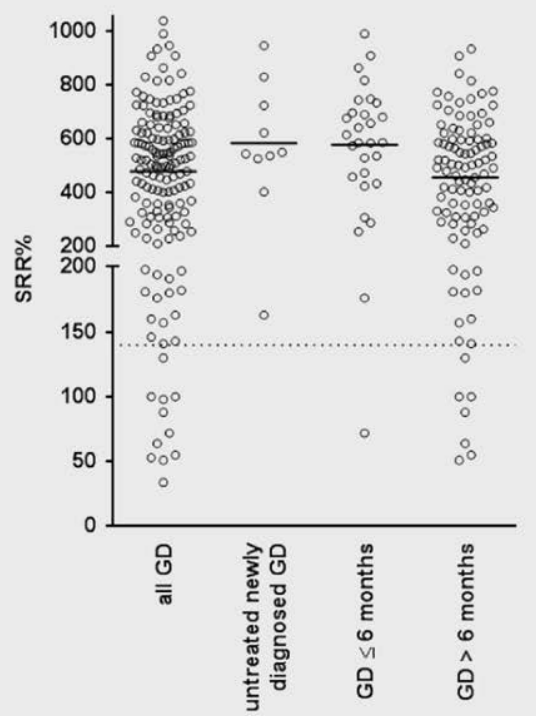

Bioassay for blocking TSHR-Ab

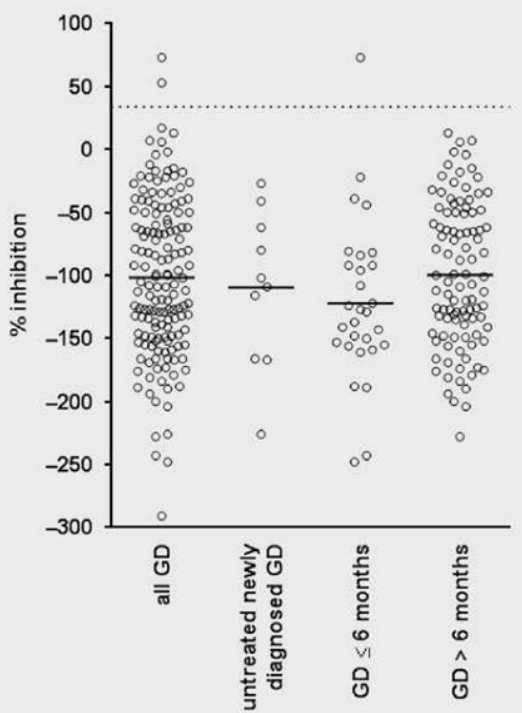

- Fig. 2 Comparison of the bridge assay and both bioassays for stimulating and blocking TSHR-Ab in patients with Graves's disease: Serum levels of TSHR-Ab in the 3 assays according to the time interval since initial diagnosis of Graves' disease. 


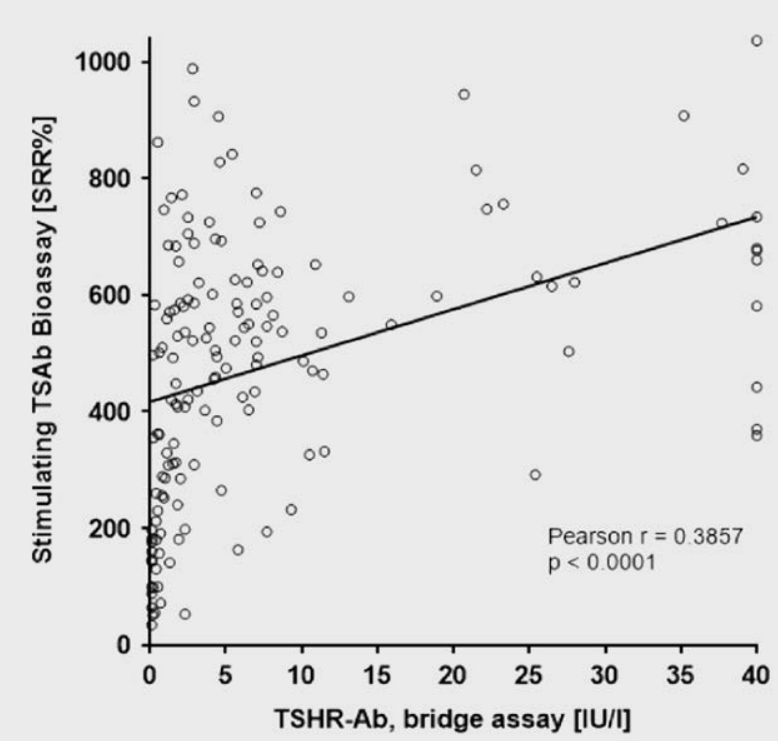

- Fig. 3 Correlation analysis of a bridge immunoassay and a bioassay for stimulating TSHR-Ab: The bridge immunoassay and the stimulatory TSAb bioassay correlated positively (Pearson, $r=0.386$, $\mathrm{p}<0.001)$.

(125/151 GD samples) between these two assays. Since two GD patients were TSAb-negative in the bioassay but positive in both the Immulite assay and TBAb bioassay, the previously reported [ 20 , $21,23]$ unspecific detection of TBAb with the bridge assay has to be acknowledged.

To better understand any differences in the detection of TSHRAb between the bridge assay and the bioassay, the TSHR constructs of both assays need to be considered. As far as is known the MC4 molecules used in both assays are likely identical. The manufacturer of the TSAb bioassay obtained the SG5-MC4 plasmid from the Kohn laboratory that originally generated the MC4 construct [32]. SG5-MC4 was used then to generate a plasmid that also contained the luciferase gene that was then used to generate the MC4-CHOluc cell line [32]. No alteration to the MC4 sequence was made during the cloning [32]. The nucleotide sequence of the MC4 construct was determined, which allowed the JGU lab to state exactly which amino acid (AA) residues from the rat LHCGR were inserted and which AA residues from the human TSHR were deleted [14]. Tahara et al. $[14,15]$ stated that they performed sequencing, but did not publish their sequence data of the MC4 molecule. In comparison, the sequence of the MC4 published in Clin Exp Immunol 2010 (Figure 1 of the publication) [32] indicated several minor differences from what is indicated in Tahara et al. [14] as follows:

\footnotetext{
- 262-368 deleted from the hTSHR (rather than 262-370 as stated in [14])

- 262-334 inserted from rat LHCGR (rather than 262-329 as stated in [14])

- $S$ to $R$ change at AA residue 287 of the rat LHCGR
}

Since the DNA sequence of the MC4 in the Tahara plasmid (SG5MC4) was determined, we suspect that these apparent differences were due to Tahara and co-workers inadvertently misstating their AA sequences. Finally, Leonard Kohn is an author of the Clin Exp Immunol 2010 paper [32] and concurred with the published data. It is also important to emphasize that the cell-based bioassay for measuring stimulating TSHR-Ab employs exactly the same MC4-construct used in all publications from the JGU Lab.

According to the informations given by the manufacturer of the bridge assay (personal communication with MS) this assay also uses the potentially identical MC4 molecule for TSHR-Ab detection as described by Tahara and co-workers. As far as we know, the automated bridge assay is also based on the identical MC 4 construct which has been described by the group of Dr. Loos and co-workers for a manual TSHR-Ab assay [12]. To the best of our knowledge there is, however, no published information available as to whether the MC4 construct used in the bridge-assay has been sequenced or not. Looking carefully at the published sequences of the various chimeras in the patent of Dr. Loos (United States Patent Loos 8999727 April 7, 2015), the sequence data in the patent (especially chimera B and sequence No. 2 and 4) do not show the complete chimeric molecule (only seven amino acids of the rat $\mathrm{LH}$ receptor are shown; the C-terminal part of the extracellular domain of the human TSH receptor is completely shown and is identical to the amino acid sequence of this part of the bioassay MC4 construct). Unfortunatley there is no reference to the 8999727 patent of Dr. Loos in the Immulite package insert. Taken together, if the MC4 molecule used within the bridge assay (including the amino acid "changes" described above) is identical to the MC4 molecule used in the bioassay, the antibody recognition in both assays should be identical. So far, however, no detailed information regarding MC4 construct used in the bridge assay are available to answer this question.

Furthermore, M22 is positive in both assays [21], which is consistent with the fact that the epitope for M22 is present in the receptor used in both assays. As previously reported [33] and confirmed [2], there is significant overlap in the binding epitopes of stimulating and blocking TSHR-Ab on the TSHR. Therefore, it is unlikely that the chimeric MC4 TSHR is specific for TSAb. Furthermore, the data of Tahara et al. on the TSAb specificity of MC4 have not been reproduced. As additional evidence that MC4 is not TSAb specific, a bioassay for measuring blocking TSHR-Ab utilizing the same MC4 cell line used in the TSAb bioassay was developed, validated and evaluated using a human monoclonal blocking antibody (K1-70) and human serum samples that were TSHR-Ab-positive and TSAb-negative [16, 18]. This, now CE-marked, TBAb bioassay has performed well in identifying blocking antibodies in patients with GD and HT.

It is unlikely that the readout could affect the results and explain discrepancies between the bioassays and immunoassays. However, the two aforementioned blocking antibody (TBAb)-positive patients with GD were positive in both the bridge assay as well as in the Cobas binding assay despite major differences in design. In fact, binding assays, generally give similar results despite differences in their design and readout.

In conclusion, the bridge immunoassay and the two bioassays are highly sensitive assays for the detection of TSHR-Ab in patients with GD. If the chimeric TSHR molecules used in both assays are es- 
sentially identical, then one would expect that the antibody recognition (TSAb and TBAb) should be identical too. Data are not, however, available to discern this with certainty. Regardless of the TSHR construct used, at the present time the functionality of TSHR antibodies can be only confirmed with a dynamic cell-based bioassay.

\section{Conflict of Interest}

SA, TD, ME, MK, and DH have nothing to disclose. MS received from Siemens honoraria for oral presentations. GJK consults for and the JGU Lab has received research grants from Quidel.

\section{References}

[1] Bartalena L. Diagnosis and management of Graves disease: A global overview. Nat Rev Endocrinol 2013; 9: 724-734

[2] Furmaniak J, Sanders J, Nunez Miguel R et al. Mechanisms of action of TSHR autoantibodies. Horm Metab Res 2015; 47: 735-752

[3] Morshed SA, Davies TF. Graves' Disease Mechanisms: The role of stimulating, blocking, and cleavage region TSH receptor antibodies. Horm Metab Res 2015; 47: 727-734

[4] Costagliola S, Morgenthaler NG, Hoermann R et al. Second generation assay for thyrotropin receptor antibodies has superior diagnostic sensitivity for Graves' disease. J Clin Endocrinol Metab 1999; 84: 90-97

[5] Shewring G, Smith BR. An improved radioreceptor assay for TSH receptor antibodies. Clin Endocrinol (Oxf) 1982; 17: 409-417

[6] Schott M, Hermsen D, Broecker-Preuss M et al. Clinical value of the first automated TSH receptor autoantibody assay for the diagnosis of Graves' disease (GD): An international multicentre trial. Clin Endocrinol (Oxf) 2009; 71: 566-573

[7] Araki N, lida M, Amino $\mathrm{N}$ et al. Rapid bioassay for detection of thyroidstimulating antibodies using cyclic adenosine monophosphate-gated calcium channel and aequorin. Eur Thyroid J 2015; 4: 14-19

[8] Diana T, Kanitz M, Lehmann M et al. Standardization of a bioassay for thyrotropin receptor stimulating autoantibodies. Thyroid 2015; 25: 169-175

[9] Giuliani C, Cerrone D, Harii N et al. A TSHR-LH/CGR chimera that measures functional thyroid-stimulating autoantibodies (TSAb) can predict remission or recurrence in Graves' patients undergoing antithyroid drug (ATD) treatment. J Clin Endocrinol Metab 2012; 97: E1080-E1087

[10] Lytton SD, Ponto KA, Kanitz M et al. A novel thyroid stimulating immunoglobulin bioassay is a functional indicator of activity and severity of Graves' orbitopathy. J Clin Endocrinol Metab 2010; 95: 2123-2131

[11] Diana T, Daiber A, Oelze M et al. Stimulatory TSH-Receptor antibodies and oxidative stress in graves disease. J Clin Endocrinol Metab 2018; 103: 3668-3677

[12] Frank CU, Braeth S, Dietrich JW et al. Bridge technology with TSH receptor chimera for sensitive direct detection of TSH receptor antibodies causing Graves' disease: Analytical and clinical evaluation. Horm Metab Res 2015; 47: 880-888

[13] Rapoport B, Chazenbalk GD, Jaume JC et al. The thyrotropin (TSH) receptor: Interaction with TSH and autoantibodies. Endocr Rev 1998; 19: $673-716$

[14] Tahara K, Ban T, Minegishi T et al. Immunoglobulins from Graves' disease patients interact with different sites on TSH receptor/LH-CC receptor chimeras than either TSH or immunoglobulins from idiopathic myxedema patients. Biochem Biophys Res Commun 1991; 179: $70-77$
[15] Tahara K, Ishikawa N, Yamamoto K et al. Epitopes for thyroid stimulating and blocking autoantibodies on the extracellular domain of the human thyrotropin receptor. Thyroid 1997; 7: 867-877

[16] Li Y, Kim J, Diana T et al. A novel bioassay for anti-thyrotrophin receptor autoantibodies detects both thyroid-blocking and stimulating activity. Clin Exp Immunol 2013; 173: 390-397

[17] Kampmann E, Diana T, Kanitz M et al. Thyroid stimulating but not blocking autoantibodies are highly prevalent in severe and active thyroid-associated orbitopathy: A prospective study. Int J Endocrinol 2015; 678194

[18] Diana T, Li Y, Olivo PD et al. Analytical performance and validation of a bioassay for thyroid-blocking antibodies. Thyroid 2016; 26: 734-740

[19] Bossowski A, Moniuszko M, Idzkowska E et al. Decreased proportions of $\mathrm{CD} 4+\mathrm{IL} 17+/ \mathrm{CD} 4+\mathrm{CD} 25+\mathrm{CD} 127-$ and $\mathrm{CD} 4+\mathrm{IL} 17+/ \mathrm{CD} 4+\mathrm{CD} 25+$ CD127 - FoxP3 + T cells in children with autoimmune thyroid diseases. Autoimmunity 2016; 49: 320-328

[20] Diana T, Wuster C, Kanitz M et al. Highly variable sensitivity of five binding and two bio-assays for TSH-receptor antibodies. J Endocrinol Invest 2016; 39: 1159-1165

[21] Diana T, Wuster C, Olivo PD et al. Performance and specificity of 6 immunoassays for tsh receptor antibodies: A multicenter study. Eur Thyroid J 2017; 6: 243-249

[22] Diana T, Krause J, Olivo PD et al. Prevalence and clinical relevance of thyroid stimulating hormone receptor-blocking antibodies in autoimmune thyroid disease. Clin Exp Immunol 2017; 189: 304-309

[23] Diana T, Olivo PD, Kahaly G]. Thyrotropin receptor blocking antibodies. Horm Metab Res 2018; 50: 853-862

[24] Leschik J], Diana T, Olivo PD et al. Analytical performance and clinical utility of a bioassay for thyroid-stimulating immunoglobulins. Am J Clin Pathol 2013; 139: 192-200

[25] Ross DS, Burch HB, Cooper DS et al. 2016 American Thyroid Association Guidelines for Diagnosis and Management of Hyperthyroidism and Other Causes of Thyrotoxicosis. Thyroid 2016; 26: 1343-1421

[26] Kahaly G], Bartalena L, Hegedüs L et al. European Thyroid Association Guideline for the management of Graves' hyperthyroidism. Eur Thyroid J 2018; 167-186

[27] Allelein S, Ehlers M, Goretzki S et al. Clinical evaluation of the first automated assay for the detection of stimulating TSH receptor autoantibodies. Horm Metab Res 2016; 48: 795-801

[28] Tozzoli R, D’Aurizio F, Villalta D et al. Evaluation of the first fully automated immunoassay method for the measurement of stimulating TSH receptor autoantibodies in Graves' disease. Clin Chem Lab Med 2017; 55: 58-64

[29] Diana T, Brown RS, Bossowski A et al. Clinical relevance of thyroid-stimulating autoantibodies in pediatric graves' disease-a multicenter study. J Clin Endocrinol Metab 2014; 99: 1648-1655

[30] Kemble D], Jackson T, Morrison M et al. Analytical and clinical validation of two commercially available immunoassays used in the detection of TSHR antibodies. J Appl Lab Med 2017; 2: 345-355

[31] Diana T, Kahaly G]. Thyroid stimulating hormone receptor antibodies in thyroid eye disease-methodology and clinical applications. Ophthalmic Plast Reconstr Surg 2018; 34: S13-S19

[32] Lytton SD, Li Y, Olivo PD et al. Novel chimeric thyroid-stimulating hormone-receptor bioassay for thyroid-stimulating immunoglobulins. Clin Exp Immunol 2010; 162: 438-446

[33] Furmaniak J, Sanders J, Rees Smith B. Blocking type TSH receptor antibodies. Auto Immun Highlights 2013; 4: 11-26 